\title{
PENGARUH KONSENTRASI NaOH TERHADAP UKURAN KRISTAL ZEOLIT A YANG DISINTESIS DARI LIMBAH GEOTHERMAL
}

\author{
Deni Fajar Fitriyana $^{1}$, Sulardjaka $^{1}$, Norman Iskandar ${ }^{1}$ dan M.Dzulfikar ${ }^{2}$ \\ ${ }^{1}$ Departemen Teknik Mesin, Fakultas Teknik, Universitas Diponegoro \\ Jl. Prof. H. Soedarto, Tembalang, Kota Semarang 50275. \\ ${ }^{2}$ Jurusan Teknik Mesin, Fakultas Teknik, Universitas Wahid Hasyim \\ Jl. Menoreh Tengah X/22, Sampangan, Semarang 50236 \\ *Email: deniifa89@gmail.com
}

\begin{abstract}
Abstrak
Telah dilakukan sintesis zeolite berbahan dasar limbah geothermal dari Pembangkit Listrik Tenaga Panas Bumi (PLTP) Geo Dipa Energi, Dieng, Wonosobo, Jawa Tengah. Penelitian ini bertujuan untuk meneliti pengaruh konsentrasi $\mathrm{NaOH}$ terhadap karakteristik zeolit yang disintesis dari limbah geothermal. Sebelum digunakan sebagai bahan dasar sintesis, lumpur geothermal terlebih dahulu dilakukan kalsinasi pada suhu $850^{\circ} \mathrm{C}$ selama 3 jam. Sintesis menggunakan metode hydrothermal pada suhu100 ${ }^{\circ} \mathrm{C}$ selama 4 jam dengan variasi konsentrasi NaOH 1,67 M, 3M dan 5M. Karakterisasi produk sintesis dilakukan dengan menggunakan spektroskopi serapan atom (AAS), difraktometer sinar-x (XRD) dan scanning electron microscope (SEM). Dari hasil uji AAS kandungan silika pada lumpur geothermal setelah proses kalsinasi meningkat dari 49,1\% menjadi $80.0426 \%$. Dari hasil analisis data XRD dan SEM, peningkatan konsentrasi $\mathrm{NaOH}$ akan menurukan crystal sizes dan crystallization time zeolite A.
\end{abstract}

Kata Kunci: sintesis, hidrotermal, zeolit A, sodalit

\section{PENDAHULUAN}

Penggunaan energi panas bumi sebagai Pembangkit Listrik Tenaga Panas Bumi (PLTP) memberikan dampak positif pada pembangunan nasional, karena panas bumi merupakan energi terbarukan yang ketersediaannya melimpah. Namun dampak negatif penggunaan panas bumi sebagai sumber energi adalah produksi energi panas bumi menghasilkan limbah. Limbah yang dihasilkan berupa geothermal brine dan sludge. Limbah padat (sludge) berasal dari endapan pada proses pengolahan limbah cair (geothermal brine) dan kerak silika dari pipapipa instalasi Pusat Listrik Tenaga Panas Bumi (PLTP). Karakterisasi pada geothermal sludge menunjukan kandungan silica ( $\mathrm{SiO} 2)$ sebesar $50,20 \%$ (Sulardjaka, 2014). Dalam proses sintesis zeolite, masalah terbesar adalah ketersedian dan mahalnya harga $\mathrm{SiO} 2$ sebagai bahan dasar dalam proses sintesis. Besarnya kandungan $\mathrm{SiO} 2$ pada geothermal sludge merupakan solusi bahan baku untuk proses pembuatan zeolite sintesis (Deni Fajar Fitriyana, 2012).

Zeolite merupakan kristal alumina-silika yang mempunyai struktur berongga atau berpori dan mempunyai sisi aktif yang bermuatan negatif yang mengikat secara lemah kation penyeimbang muatan. Komposisi zeolite dapat dengan baik dijelaskan dengan tiga komponen sebagai berikut (Payra, 2003):

$$
M_{\frac{n}{m}}^{m+} \cdot\left[S i_{1-n} A l_{n} O_{2}\right] \cdot n H_{2} O
$$

Dimana :

$M_{\underline{n}}^{\text {th+ }} \quad$ merupakan extraframework kation (unsur logam)

$\left[\mathrm{Si}_{1-\mathrm{n}} \mathrm{Al}_{\mathrm{n}} \mathrm{O}_{2}\right]$ merupakan kerangka zeolit $\mathrm{nH}_{2} \mathrm{O} \quad$ merupakan sorbed phase

Zeolite terbagi atas dua jenis berdasar asalnya yaitu zeolite alam dan zeolite sintetis. Zeolite sintesis adalah material yang meliki sifat fisik dan kimia yang hampir sama dengan sifat fisik dan kimia dari material zeolite alam. Zeolite sintetis lebih sering digunakan untuk kepentingan komersial dibandingkan dengan zeolite alam, hal ini dikarenakan keseragaman ukuran partikel dan tingkat kemurnian yang tinggi pada zeolit sintetis. Keuntungan lainnya struktur zeolit sintetis adalah dapat dibuat sesuai dengan yang diinginkan (Sri Sugiarti, 2017).

Dalam penelitian ini akan dilakukan sintesis zeolite secara hydrothermal berbahan dasar lumpur geothermal yang didapat dari PLTP Dieng dengan variasi konsentrasi $\mathrm{NaOH}$ $1,67 \mathrm{M}, 3 \mathrm{M}, 5 \mathrm{M}$ pada suhu $100^{\circ} \mathrm{C}$ selama 4 jam dengan $\mathrm{pH}>12$. Penelitian ini dilakukan untuk mengetahui pengaruh konsentrasi $\mathrm{NaOH}$ 
terhadap struktur, morfologi, kirstalisasi dan ukuran kristal zeolite yang terbentuk.

\section{METODE PENELITIAN \\ Preparasi Geothermal Sludge}

Serbuk geothermal dari PLTP dieng dijemur dan dikeringkan. Setelah kering, dilakukan proses penganyakan dengan ukuran mesh 100. Kemudian dilanjutkan dengan pengujian AAS dan XRD untuk mengetahui komposisi kimia dan fasa kristalin pada serbuk geothermal. Tahap selanjutnya adalah menghilangkan senyawa organik didalam serbuk geothermal dengan proses kalsinasi menggunakan tungku oven charbolite pada suhu $850^{\circ} \mathrm{C}$ selama 3 jam (Deni Fajar Fitriyana, 2018), Untuk mengetahui perubahan komposisi kimia dan perubahan fasa kristalinnya, dilakukan pengujian AAS dan XRD.

\section{Pembuatan Natrium Aluminat}

Pembuatan larutan natrium aluminat dimulai dengan melarutkan 20 gr $\mathrm{NaOH}$ kedalam $100 \mathrm{~mL}$ aquades. Larutan yang terbentuk dimasukan kedalam gelas kaca, kemudian tempatkan pada magnetic stirrer. Magnetic stirrer diatur pada suhu $100^{\circ} \mathrm{C}$ dan dengan kecepatan putaran 300 rpm. 8,5 gr $\mathrm{Al}$ $(\mathrm{OH})_{3}$ ditambahkan sedikit demi sedikit kedalam larutan $\mathrm{NaOH}$ yang sudah dipanaskan. Proses ini dilakukan selama 20 menit sehingga terbentuk larutan natrium aluminat tanpa adanya pengendapan (Deni Fajar Fitriyana, 2013)

\section{Pembuatan Natrium Silikat}

$30 \mathrm{~mL}$ natrium aluminat dari proses sebelumnya dicampur dengan $30 \mathrm{~mL}$ larutan $\mathrm{NaOH} 5 \mathrm{M}, \mathrm{NaOH} 3 \mathrm{M}$ dan $\mathrm{NaOH} 1,67 \mathrm{M}$. Kemudian tambahkan 3 gr serbuk geothermal yang telah dikalsinasi. Pencampuran dilakukan menggunakan magnetic stirer yang telah diatur pada suhu $30^{\circ} \mathrm{C}$ dengan kecepatan putaran 300 rpm. Proses pencampuran tersebut dilakukan selama 2 jam untuk memperoleh larutan natrium silikat yang bersifat homogen [6]. Natrium silikat yang dihasilkan dimasukkan ke dalam tabung teflon kemudian ditempatkan pada alat hydrothermal. Proses sintesis dimulai dengan pemanasan sampai suhu air didalam reaktor sebesar $100^{\circ} \mathrm{C}$, kemudian dilakukan penahanan (holding time) selama 4 jam. Hasil yang terbentuk kemudian disaring dengan kertas saring whatmann untuk memisahkan antara padatan dan filtrate. Padatan yang terbentuk dicuci dengan larutan aquabidest dan dikeringkan dengan oven pada suhu $70^{\circ} \mathrm{C}$ selama 3 jam untuk mendapatkan hasil akhir yaitu serbuk zeolite.

\section{HASIL DAN PEMBAHASAN \\ Karakterisasi Serbuk Geothermal}

Tabel 1 menunjukan komposisi kimia serbuk geothermal dari hasil pengujian AAS. Sebelum preparasi, kandungan $\mathrm{SiO}_{2}$ serbuk geothermal sebesar 49,10\%. Sedangkan kandungan $\mathrm{Al}_{2} \mathrm{O}_{3}$ sangat kecil yaitu hanya $0.0559 \%$. Untuk mendapatkan serbuk geothermal dengan kandungan $\mathrm{SiO}_{2}$ yang lebih tinggi maka harus dilakukan kalsinasi pada suhu $850^{\circ} \mathrm{C}$ selama 3 jam. Proses kalsinasi ini bertujuan untuk menghilangkan komponen organik yang dapat menguap pada temperatur yang cukup tinggi. Setelah preparasi, kandungan $\mathrm{SiO}_{2}$ serbuk geothermal sebesar $80,0426 \%$ dan kandungan $\mathrm{Al}_{2} \mathrm{O}_{3}$ sebesar $0.142067 \%$.

Tabel 1 Hasil pengujian AAS sebelum dikalsinasi

\begin{tabular}{|c|l|c|c|}
\hline NO & Parameter & Sebelum Preparasi(\%) & Setelah Preparasi (\%) \\
\hline 1 & $\mathrm{~A} 12 \mathrm{O} 3$ & 0.0559 & 0.142067 \\
\hline 2 & $\mathrm{Fe} 2 \mathrm{O} 3$ & 0.1919 & 0.4506 \\
\hline 3 & $\mathrm{Na} 2 \mathrm{O} 3$ & 0.6088 & 0.7601 \\
\hline 4 & $\mathrm{SiO} 2$ & 49.1 & 80.0426 \\
\hline
\end{tabular}

Gambar 1 menunjukan difraktogram serbuk geothermal sebelum kalsinasi (a) dan setelah kalsinasi (b). Gambar 1 (a) menunjukan serbuk geothermal hanya mengandung silika non kristal atau berbentuk amorf. Sedangkan Gambar 1(b) ditemukan peak pada $2 \theta 21.91$ dan 20.88 yang memiliki intensitas relatif sebesar 100 dan 40. Berdasarkan data pada software JCPDS, peak tersebut menunjukan terbentuknya silika mikrokristal yaitu cristobalite (JCPDS nomer 03-0267) (Deni Fajar Fitriyana, 2013).

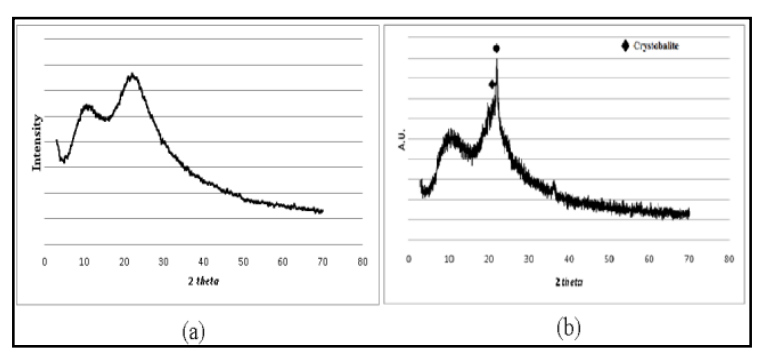

Gambar 1 Difraktogram serbuk geothermal sebelum kasinasi (a) dan setelah kalsinasi(b) 


\section{Karakterisasi Padatan Hasil Sintesis}

Tabel 2 menunjukan hasil uji AAS pada produk hasil sisintesis. Berdasarkan hasil AAS, rasio $\mathrm{Si} / \mathrm{Al}$ dalam zeolit sintesis dengan metode hydrothermal sebesar 1,788. Hal ini sesuai dengan literatur bahwa zeolit A memiliki perbandingan rasio $\mathrm{Si} / \mathrm{Al}$ 1-3,5 (Byrappa, 2001).

Tabel 2 Hasil analisis rasio $\mathrm{Si} / \mathrm{Al}$ dengan AAS

\begin{tabular}{|c|c|c|}
\hline No & Parameter & Komposisi (\%) \\
\hline 1 & $\mathrm{~A} 1$ & 5.865333 \\
\hline 2 & $\mathrm{Si}$ & 10.48667 \\
\hline
\end{tabular}

Gambar 2 menunjukan hasil uji XRD pada zeolite setelah proses sintesis dengan variasi konsentrasi $\mathrm{NaOH} 1,67 \mathrm{M}, 3 \mathrm{M}$ dam $5 \mathrm{M}$ dengan suhu hydrothermal $100^{\circ} \mathrm{C} \quad 4$ jam. Berdasarkan hasil XRD menunjukan adanya kesesuian peak dari difraktogram zeolite hasil sintesis terhadap data JCPDS nomor 11-0401 (Sodalite) dan nomor 31-1269 (Zeolit A) [6]. Sehingga dapat disimpulkan pada ketiga variasi konsentrasi $\mathrm{NaOH}$ terbentuk zeolit $A$ dan sodalit. Untuk menentukan ukuran butir suatu kristal zeolite sintesis menggukan persamaan scherrer (Hamdan, 1992).

$$
\mathrm{L}=\frac{57.3 \times k \times \lambda}{\mathrm{FWHM} \times \cos \theta}
$$

Keterangan:

$\begin{array}{lll}\mathrm{L} & = & \text { Ukuran bulir Kristal }(\mathrm{nm}) \\ \mathrm{k} & = & \text { Suatu konstanta oksida }(0,94) \\ \lambda & = & \begin{array}{l}\text { Panjang gelombang sinar } \mathrm{X} \\ \text { saat pengujian }(1,5406 \AA)\end{array} \\ \mathrm{FWHM}= & \begin{array}{l}\text { Full width half maximum } \\ \text { (lihat data pengujian) }\end{array} \\ \theta & = & \begin{array}{l}\text { Sudut posisi puncak difraksi } \\ \text { Kristal }\end{array} \\ 57,3= & \begin{array}{l}\text { Faktor koreksi dari derajat } \\ \text { ke radian }\end{array}\end{array}$

Dengan nilai FWHM dan $\theta$ terdapat pada Tabel 3.

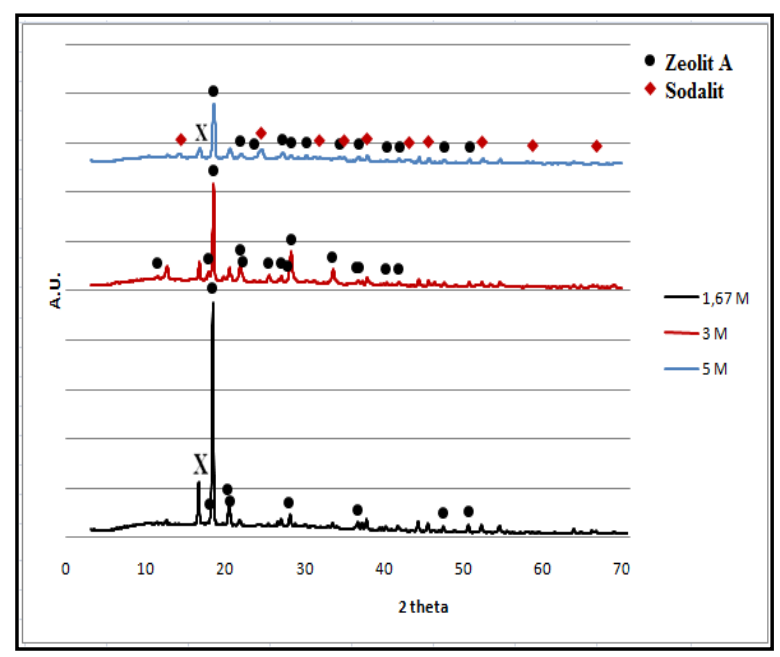

Gambar 2 Difraktogram tiga variasi zeolit hasil sintesis

Tabel 3 Nilai 2 theta dan FWHM pada peak tertinggi pada Gambar 2

\begin{tabular}{|c|c|c|}
\hline Konsentrasi $\mathrm{NaOH}$ & 2 theta & FWHM \\
\hline $1,67 \mathrm{M}$ & 18,4005 & 0,19230 \\
\hline $3 \mathrm{M}$ & 18,4882 & 0,23020 \\
\hline $5 \mathrm{M}$ & 18,5325 & 0,3890 \\
\hline
\end{tabular}

Dari hasil perhitungan didapatkan ukuran kristal zeolite A menggukan persamaan scherrer pada variasi konsentrasi $\mathrm{NaOH} 1,67 \mathrm{M}$, $3 \mathrm{M}, 5 \mathrm{M}$ dengan waktu pemanasan 4 jam masing - masing sebesar 43,67 nm ; 36,52 nm; dan 21,56 $\mathrm{nm}$. Untuk mengetahui pengaruh konsentrasi $\mathrm{NaOH}$ terhadap ukuran kristal zeolit yang dihasilkan, disajikan Gambar 3 .

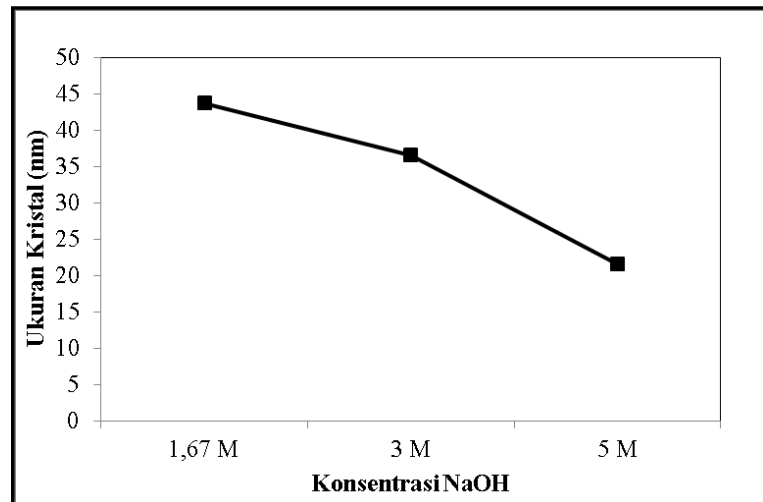

Gambar 3 Pengaruh konsentrasi $\mathrm{NaOH}$ terhadap ukuran kristal zeolit A pada waktu pemanasan 4 jam

Gambar 3 merupakan grafik pengaruh peningkatan konsentrasi $\mathrm{NaOH}$ terhadap penurunan ukuran kristal zeolit A yang dihasilkan pada waktu pemanasan 4 jam. Fenomena ini terjadi karena setiap peningkatan konsentrasi $\mathrm{NaOH}$ akan berakibat pada kristalisasi yang terajadi menjadi lebih cepat. 
Karena kristalisasi yang lebih cepat, maka ukuran kristal zeolit A yang dihasilkan akan semakin kecil (Lobo, 2003). Dengan kata lain ukuran kristal dari zeolit A selama sintesis dengan metode hydrothermal menurun dengan peningkatan konsentrasi $\mathrm{NaOH}$ (Wang, 2008).

Hasil SEM pada zeolite sintesis dengan variasi konsentrasi $\mathrm{NaOH}$ ditunjukan pada Gambar 4. Kristal zeolit A mempunyai bentuk kubus karena disusun oleh polyhedra yang dihasilkan dari 4 cincin tetrahedra yang saling berikatan ganda (D4R) (Wajima, 2005). Hasil pengujian SEM pada Gambar 4 (A), (B) dan (C) ditemukan adanya partikel berbentuk kubus yang menunjukan struktur zeolite A.

Selain itu terdapat partikel yang berbentuk spherical diantara struktur zeolit A yang berbentuk kubus. Adanya partikel berbentuk spherical mengindikasikan adanya konversi dari fasa metastabil menjadi kristal zeolit yang lebih stabil dengan menggunakan metode hydrothermal (Ojha, 2004).

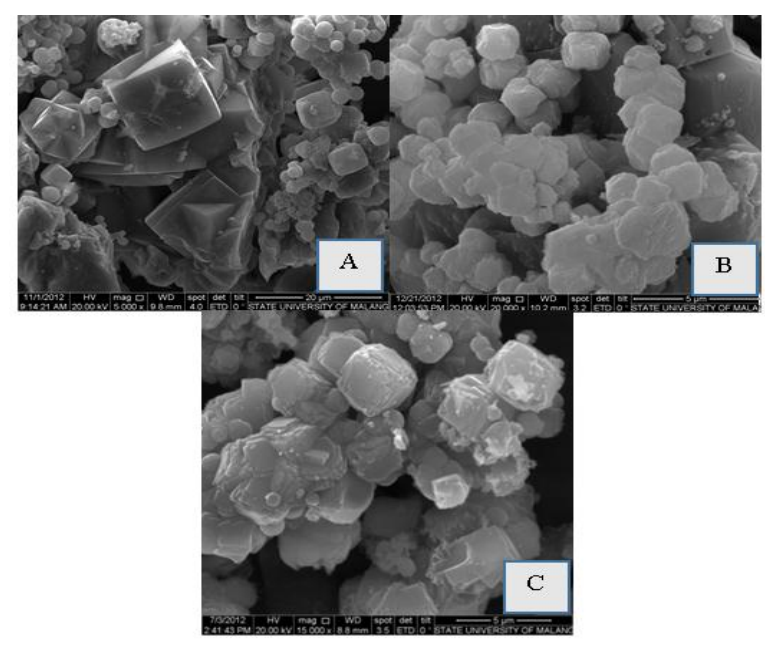

Gambar 4 Hasil pengujian SEM terhadap zeolit sintesis dengan variasi konsentrasi NaOH 1,67 M (A), 3 M (B) dan 5 M (C).

\section{KESIMPULAN}

Berdasarkan penelitian yang telah dilakukan, maka dapat di ambil kesimpulan:

1. Serbuk geothermal memiliki kandungan silika sebesar 80,0426\% sehingga dapat digunakan sebagai sumber silika dalam sintesis zeolit.

2. Zeolit yang disintesis dari serbuk geothermal menghasilkan zeolit jenis zeolit A dan Sodalit. Peningktan konsentrasi $\mathrm{NaOH}$ akan mempercepat kecepatan kristalisasi zeolit A sehingga akan menurunkan ukuran kristal zeolit sintesis dengan bahan dasar serbuk geothermal.

\section{DAFTAR PUSTAKA}

Byrappa, K., Yoshimura, Masahiro (editor)., (2001), Hydrothermal Synthesis and Growth of Zeolites in Handbook of Hydrothermal Technology, University of Mysore Manasagangotri Mysore, India \& Tokyo Institute of Technology Yokohama, Japan.

Deni Fajar Fitriyana, (2013), Pengaruh Konsentrasi $\mathrm{NaOH}$ Dan Waktu Pemanasan Hydrothermal Terhadap Kristalisasi Zeolit A Yang Disintesis Dari Limbah Geothermal, Jurusan Teknik Mesin, Fakultas Teknik, Universitas Diponegoro.

Deni Fajar Fitriyana, Sulardjaka, (2012), Sintesis Zeolit A Berbahan Dasar Limbah Geothermal Dengan Metode Hidrotermal, Simposium Nasional Rapi XI FT UMS : 42-47.

Deni Fajar Fitriyana, Sulardjaka, Norman Iskandar, M. Dzulfikar, (2018), Pengaruh Suhu Hydrothermal Terhadap Karakteristik Zeolit Yang Disintesis Dari Limbah Geothermal, Jurnal Ilmiah MOMENTUM volume $14: 46-50$.

Hamdan, H. (1992). Introduction to Zeolites Synthesis, Characterization and Modifications. University Technology Malaya. Malaysia.

Lobo, Raul F., (2003), Introduction to the Structural Chemistry of Zeolites, University of Delaware, U.S.A.

Ojha, K., Pradhan, N., dan Samanta, A., (2004), Zeolite from fly ash: synthesis and characterization. Bull. Mater. Sci.(27) : 555-564.

Payra, Pramatha and Dutta, Prabir K., (2003), Handbook Of Zeolite Science And Technology, The Ohio State University Columbus Ohio, U.S.A.

Sri Sugiarti, Charlena, Nurul Afiati Aflakhah, (2017), Zeolit Sintetis Terfungsionalisasi 3- Trimetoksisilil)-1-Propantiol sebagai Adsorben Kation Cu(II) dan Biru Metilena, Jurnal Kimia VALENSI: Jurnal Penelitian dan Pengembangan Ilmu Kimia : 11-19.

Sulardjaka, D.F. Fitriyana, and A.P. Adi, (2014), Synthesis of Zeolite from Geothermal Waste, Applied Mechanics and Materials Vol. 660 : 157-161. 
Wajima, T. H., Mioko,K., Keiko, I., Hiroji, T., Osamu, I., Kazuhiko, N. T., Downsd, Robert T. Rakovan, John F. (2005). Zeolite synthesis from paper sludge ash at low temperature $\left(90^{\circ} \mathrm{C}\right)$ with addition of diatomite. Journal of Hazardous Materials B (132) : 244-252.

Wang, C. F., Sheng Li, J., Jun Wang, L., Sun, X. Y., (2008), Influence of $\mathrm{NaOH}$ concentrations on synthesis of pure-form zeolite A from fly ash using two-stage method, Journal of Hazardous Materials $155: 58-64$. 